\title{
A reinvenção da aura e outras considerações sobre a fotografia
}

\section{Carolina Junqueira dos Santos (UFMG)}

Resumo: O presente artigo tem como objeto de estudo a teoria benjaminiana da destruição da aura e sua possível reinvenção na imagem fotográfica através da mudança na percepção do homem moderno. A fotografia, como emblema da imagem técnica, rompeu com valores de autenticidade e unicidade, comuns à imagem até o século XIX, e dela emergiram novos aspectos auráticos, novos valores de unicidade $\mathrm{e}$ autenticidade que remetem menos ao objeto que à informação que ele guarda.

Palavras-chave: Walter Benjamin. Aura. Fotografia.

As fotos são, talvez, os mais misteriosos de todos os objetos que compõem e adensam o ambiente que identificamos como moderno.

Susan Sontag

01. Breve História da Verdade

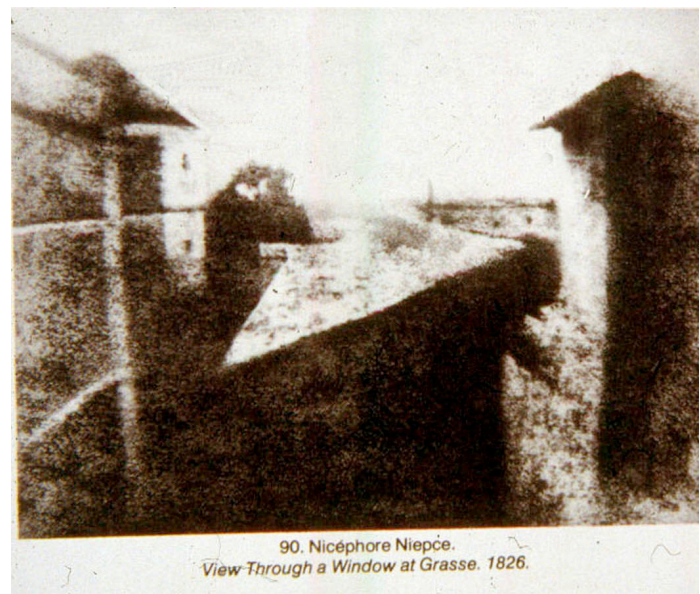

1826. Uma paisagem através da janela. Percebemos o leve contorno das coisas, algo que mais parece um desenho, talvez uma gravura em pedra, ou uma simples mancha gráfica. É a paisagem vista da janela, ou, antes, o real que se revela através da luz e que se fixa na superfície lisa de uma placa ${ }^{1}$. A fotografia conseguira, enfim, revelar-se e 
fixar-se, depois de séculos e séculos de seu quase surgimento. Explico: as técnicas que possibilitaram o surgimento da fotografia eram antigas, dizem que a estrutura ótica surgira na época de Aristóteles. Sabemos que em torno do Renascimento, a camara obscura já era bastante utilizada por pintores, a estrutura ótica de formação de imagem através de jogos de luz e de lentes estava pronta. A química veio um pouco atrás, mas há muito tempo ela se imaginava fixando imagens. Diversos testes foram realizados ao longo de séculos até que se descobriu que a prata escurecia em contato com a luz - mas como fixar a imagem escurecida?

O século XIX e o auge da modernidade trouxeram as respostas que a fotografia precisava para vir à luz. E ela veio na década de 1820, nas imagens produzidas pelo francês Nicéphore Niepce. Outro francês, Louis Daguerre, também já pesquisava há anos os meios para se chegar à fotografia e logo depois os estudos de ambos foram unidos para um maior desenvolvimento da nova técnica. Niepce morreu poucos anos depois e Daguerre acabou sendo o nome mais conhecido do advento da fotografia, tendo as primeiras imagens recebido seu nome, os famosos daguerreótipos. Muito mais tarde, descobriu-se que na mesma época outro francês, este residente no Brasil ${ }^{2}$, também estava a pesquisar e desenvolver a técnica da fotografia. Isso me leva a pensar que havia mesmo um espírito comum na época, nessa primeira metade do século XIX em especial, um espírito no qual a fotografia inevitavelmente desenvolver-se-ia. O que se chamava de progresso estava a todo vapor, tempo e espaço começavam a ser conceitos muito diferentes do que eram antigamente, as multidões lotavam as ruas e estas eram abertas à passagem de carruagens e de uma multidão anônima que logo desaparecia. O mundo se desmoronava para que outro se reconstruísse. Susan Sontag, ensaísta americana, fala desse momento em comum do surgimento da fotografia com as mudanças que a sociedade vivia, no livro Sobre Fotografia:

As câmeras começaram a duplicar o mundo no momento em que a paisagem humana passou a experimentar um ritmo vertiginoso de transformação: enquanto uma quantidade incalculável de formas de vida biológicas e sociais é destruída em um curto espaço de tempo, um aparelho se torna acessível para registrar aquilo que está desaparecendo. A melancólica Paris, de textura intricada, de Atget e Brassai, desapareceu em sua maior parte. A exemplo dos parentes e amigos mortos, preservados no álbum de família, cuja presença em fotos exorciza uma parte da angústia e do remorso inspirados por seu desaparecimento, as fotos dos arrabaldes agora devastados, das regiões rurais desfiguradas e arrasadas, suprem nossa relação portátil com o passado. ${ }^{3}$

Um outro ponto também importante era o fato da representação convencional já mostrar seus primeiros sinais de esgotamento. Havia ainda uma pintura acadêmica e naturalista, mas os ânimos modernos já lançavam a história da imagem à outra direção. A fotografia gerou um completo rearranjo no mundo das imagens e no modo de olhar. De repente, imagens podiam tratar diretamente do real e do que se chamou de "verdade". Charles Baudelaire foi um dos primeiros a se voltar contra essa ânsia pelo verdadeiro, contrapondo a isso a beleza. Desejar a verdade era, segundo ele, abrir mão do belo, era escolher o que pode ser visto ao invés do que pode ser sonhado. Em 1859, o poeta escreveu um famoso texto intitulado "O público moderno e a fotografia". Nele, sentimos a fúria baudelairiana contra a nova imagem técnica, mais exatamente contra o público 
que passou a desejar a verdade proposta pela fotografia. Chamou esta "sociedade imunda" de narcisista, lançada "à contemplação de sua imagem trivial sobre o metal"4. Afirmou que o progresso da fotografia fora mal aplicado e que isso contribuía para o empobrecimento do gênio artístico francês. Para o poeta, a fotografia deveria ser somente uma "serva das ciências e das artes, a mais humilde das servas". A pintura continuaria no reino da arte, enquanto a fotografia seria uma mera produção industrial. Para Baudelaire, pobre do homem que fizesse da técnica um espaço para a arte. E pobre da arte, que logo seria suplantada e corrompida.

Quase 8 décadas depois, Walter Benjamin publica seu famoso ensaio "A obra de arte na era de sua reprodutibilidade técnica". Num tom completamente diferente do de Baudelaire, Benjamin exalta o advento da fotografia como o advento da arte em massa e para as massas. A partir da fotografia e do seu poder de reprodução, o desejo do homem de possuir as imagens seria satisfeito. Através da reprodução técnica, a imagem perde seu caráter único, o que a emancipa também de um valor de culto. A imagem, de alguma forma, perde valores antigos e ganha outros novos. Segundo Benjamin, uma das perdas dessa nova imagem diz respeito ao que ele chama de aura. A aura existe nas obras únicas e autênticas, no original. Ela fala de uma unicidade espaço-temporal da experiência. A teoria de Benjamin é que a imagem técnica destrói a aura, e é com satisfação que ele constata isso, já que a aura era também o que conservava a arte longe do uso cotidiano, comum, das massas. Com a destruição da aura, as coisas ficam mais próximas e, segundo o teórico, a tendência das massas modernas é a de "superar o caráter único de todos os fatos através de sua reprodutibilidade" ${ }^{\circ}$. Obviamente, é preciso ter cuidado com as afirmações de Benjamin, já que seu ensaio possui um grande espírito marxista além de conter as típicas contradições de um homem moderno. Mas através dele podemos elaborar algumas reflexões, e, para este ensaio, o conceito de destruição da aura é de grande importância.

Benjamin fala também sobre uma crise na percepção: "No interior de grandes períodos históricos, a forma de percepção das coletividades humanas se transforma ao mesmo tempo que seu modo de existência"7. A fotografia, inevitavelmente, precisou criar um novo público, ou ao menos novos olhos, para lidar com ela. Até então o mundo havia visto somente imagens construídas pelo homem, pelas mãos do homem. Pela primeira vez, havia uma máquina criando imagens, e a representação jamais chegara tão perto do real como a nova imagem. Dentre o novo público, havia gente deslumbrada e gente aterrorizada - mas todos queriam, então, ser fotografados. Independente da relação que cada pessoa travara com a nova imagem técnica, uma coisa era certa: algo havia mudado definitivamente no olhar daquele século. De repente existiam imagens que eram provas de realidade. Se isso seria bom ou não, levaria tempo a descobrir - se é que já sabemos, hoje, a resposta.

Um outro ponto importante de mudança na percepção foi o olhar para a própria imagem, e Roland Barthes, em seu último livro A câmara clara, escreveu sobre isso:

Ver-se a si mesmo (e não em um espelho): na escala da História, esse ato é recente, na medida em que o retrato, pintado, desenhado ou miniaturizado, era, até a difusão da Fotografia, um bem restrito, destinado, de resto, a apregoar uma situação financeira e social - de qualquer maneira, um retrato pintado, por mais semelhante que seja (é o que procuro provar), não é uma fotografia. É curioso que não se tenha pensado no distúrbio (de civilização) que esse ato

Cadernos Benjaminianos, n. 3, Belo Horizonte, jan.-jun. 2011, p.43-54 
novo traz. Eu queria uma História dos Olhares. Pois a Fotografia é o advento de mim mesmo como outro: uma dissociação astuciosa da consciência de identidade. $^{8}$

Mais adiante, ele diz: "A Fotografia transformava o sujeito em objeto", e foi preciso então aprender a olhar esse objeto feito da própria imagem e aprender, também, a ser imagem. Barthes, 150 anos depois do advento da fotografia, diz sentir a sua própria transformação em imagem como uma microexperiência da morte: "torno-me verdadeiramente espectro"". O semiólogo francês escreveu apaixonadamente sobre fotografia, e o livro foi o seu trabalho de luto após a perda da mãe. Na morte, ele voltouse para as imagens fotográficas e tentou aprender algo sobre a perda com elas. Talvez por viver o luto no instante da escrita, talvez porque a fotografia seja mesmo indissociável da morte, seus estudos são os que mais aproximam a imagem e a perda, a ferida, o morto e o vivo que coabitam o mesmo espaço fixado em sais de prata. $\mathrm{O}$ fato é que há algo mesmo de terrível na nossa própria imagem congelada, é a visão, senão da Morte, de uma morte possível. Talvez aqueles homens do século XIX não estivessem nem perto de sentir algo semelhante, mas creio haver na fotografia, desde os seus primórdios, esse gosto pelo que não mais vive, o gosto pelo tempo congelado e pra sempre perdido.

No século XX, a fotografia acabou se tornando alvo dos jogos de ficção e um dos meios da Arte. Os fotógrafos e artistas começaram a utilizá-la para fins criativos, nos quais a "verdade" já não era um valor importante. A mídia passou a inventar imagens através de fotos, fosse alterando seu conteúdo ou mesmo recriando situações inexistentes a fim de manipular as aparências. A imagem fotográfica, que nasceu com o estatuto da verdade, acabou se tornando a grande imagem questionada e questionável. E se isso acontece em boa parte por termos aprendido a duvidar do seu conteúdo, também há um outro ponto que julgo de grande importância: o que a fotografia nos faz pensar sobre a imagem? O que ela altera no real e o que guarda dele? Benjamin falou sobre a destruição da aura, consequência da técnica na imagem, da ausência das mãos e do gesto artesanal, ausência também do gênio e da ideia de artista. Segundo o teórico alemão, qualquer pessoa poderia produzir a mesma imagem pelos meios técnicos. Mas isso não era verdade, não é verdade, a aura existe sim e continua forte. Talvez não seja tão fácil reconhecer o lugar dela na arte contemporânea, por exemplo, em relação às pinturas antigas. Mas se a aura mudou de lugar, foram também os nossos olhos que mudaram e a nossa concepção de imagem e mundo. Não existem os valores plenos de autenticidade e unicidade como existiam antes, mas existem outros e novos valores sobre o quais a fotografia nos faz refletir um pouco. Ainda segundo Benjamin, "cada um de nós pode observar que uma imagem, uma escultura e principalmente um edifício são mais

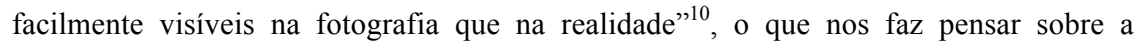
reinvenção do olhar e da percepção que a fotografia propôs aos olhos modernos. Susan Sontag escreve que "fotos podem ser mais memoráveis do que imagens em movimento porque são uma nítida fatia do tempo, e não um fluxo" "11 o que, mais uma vez, confirma a alteração que sofre o nosso olhar diante dessa realidade fatiada, fragmentada e estática. A questão de discutir se aquilo que surgia era ou não arte não é algo que interessa aqui. Interessa é perceber o que, da natureza da imagem, foi alterado com o advento da fotografia, ou, mais exatamente, o que, da natureza dos nossos olhos, transformou-se definitivamente.

Cadernos Benjaminianos, n. 3, Belo Horizonte, jan.-jun. 2011, p.43-54 
Além da já citada crise da percepção, sabemos que acontecia também naquele momento, em meio a todas as mudanças, a crise da representação. Talvez ela já viesse se construindo antes do advento da fotografia, mas foi este acontecimento que, por fim, lançou luz ao que era inevitável: a representação por si só não se sustentava mais, e a imagem fotográfica chegara a um grau de perfeição que seria inútil continuar o percurso em direção, simplesmente, à semelhança. A reprodução técnica copiava o original com toda a verdade possível, e a pintura estaria livre para fazer sua própria história a partir de então. A crise da representação gerou o modernismo e as vanguardas, a pintura refez seu lugar na arte e diversos outros meios imagéticos foram criados, de pequenos objetos a grandes instalações. A pintura nunca desapareceu por completo ao longo do século XX, mas seu uso nunca mais foi por puro desejo de reprodução do real. Com tudo o que aconteceu no século XIX, a pintura desenvolveu um lado crítico que jamais perdeu. Hoje, falar de representação é não esquecer a crise do século XIX: por mais que se represente, 150 anos não passaram em vão. A imagem não é inocente e os nossos olhos também não.

\section{Destruição e reinvenção: a inevitável aura das coisas}

Muito já se questionou as teorias benjaminianas sobre a imagem técnica, sendo o conceito de aura o que mais gerou assunto ao longo do século XX. Na verdade, todas as teorias da fotografia são ainda muito recentes se pensarmos na História da Imagem. Por isso, continuamos a tatear os espaços fotográficos, entendendo melhor hoje o que o seu advento pôde ter causado à civilização moderna. Mas ainda estamos aprendendo muito sobre eles e sobre como foram transformados o olhar e a percepção do homem.

Neste ensaio, pretendo refletir sobre a teoria benjaminiana da destruição da aura e sua possível reinvenção na imagem fotográfica. Lendo a obra de Benjamin e mantendo a devida distância entre as épocas, é possível compreender o que ele queria dizer com tal destruição que ele vira acontecer nas imagens técnicas. É fácil entender que a reprodução técnica transformava as imagens em bens possíveis para toda a sociedade, que o fim do original e da unicidade tirava a obra do seu lugar guardado, de culto, e ela deixava ver-se, expor-se. Tudo isso fica muito claro quando pensamos numa pintura, como Las Meninas, de Velázquez: a aura em torno dessa obra é inquestionável e diversos de nós, certamente, foram até Madrid exclusivamente para vê-la. Uma fotografia não nos causa isso, não há o halo dourado em torno dela. É geralmente um simples pedaço de papel (hoje pode ser um amontoado de bits) - a menos que seja uma foto antiga e/ou familiar que tenha valor afetivo e daí venha uma espécie de aura. De qualquer modo, o fato de ser facilmente reproduzida ou copiada, além de ter sido criada por um meio técnico, desfaz sim algo da aura a que Benjamin se referia. É preciso também lembrar que talvez haja um certo problema de nomenclatura no ensaio do teórico alemão, quando ele fala de reprodução, pode estar a falar tanto da reprodução de uma pintura em foto ou da própria fotografia como meio e como cópia ${ }^{12}$. Se fosse desfeito o novelo do ensaio de Benjamin, se conseguíssemos definir melhor o lugar de cada modo de reprodução, talvez não tivéssemos a sensação de equívoco quando ele fala do fim da aura.

Mas este ensaio que proponho parte do conceito básico de aura que ali ele talha e da afirmação de seu fim. Sem discutir muito o que ele entenderia ou não por aura ou pela destruição dela, quero propor um outro olhar sobre a aura na imagem fotográfica, que já não parte mais de valores de unicidade e autenticidade no objeto, mas que traz de volta esses valores a partir de outros meios. Se há, na fotografia, algo único e autêntico, isso 
diz respeito à informação que ela carrega, e não ao objeto em si. Isso me faz lembrar uma afirmação do filósofo Vilém Flusser, que em seu livro Filosofia da Caixa Preta, diz:

A fotografia enquanto objeto tem valor desprezível. Não tem muito sentido querer possuí-la. Seu valor está na informação que transmite. Com efeito, a fotografia é o primeiro objeto pós-industrial: o valor se transferiu do objeto para a informação. ${ }^{13}$

Assim, não se pode mais pensar na fotografia sendo da mesma ordem que as outras imagens existentes até então. Ela é feita de outra matéria e a partir de outra matéria, é uma técnica que, literalmente, suga a luz do real e o converte em imagem. Se o que interessa nela é a informação e não exatamente o objeto (a menos que tenha um valor de antiguidade ou de afeto), então é preciso pensar suas questões e, no caso deste ensaio, a aura da imagem, a partir de suas especificidades. É Barthes quem diz: "Seja o que for o que ela dê a ver e qualquer que seja a maneira, uma foto é sempre invisível: não é ela que vemos." ${ }^{14}$ Vemos algo que ronda o real, por menos que saibamos exatamente qual a carga de realidade, de verdade, do que vemos. Para que algo seja fotografado, é preciso existir, diferentemente da pintura, que pode criar cenas, situações e coisas inexistentes. Hoje isso pode ser bastante questionado, tendo em vista a quantidade de retoques e invenções que se fazem nas imagens, mas em essência a foto diz respeito a algo que existiu. Vemos simplesmente a superfície das coisas, a aparência, mas seja como for, é uma prova de realidade. "A sabedoria suprema da imagem fotográfica", segundo Sontag, "é dizer: 'Aí está a superfície. Agora, imagine - ou, antes, sinta, intua - o que está além, o que deve ser a realidade, se ela tem este aspecto'. Fotos, que em si mesmas nada podem explicar, são convites inesgotáveis à dedução, à especulação e à fantasia."15 No fim das contas, mesmo lidando com traços do real, a fotografia também é um espaço de fantasia e de criação. Quando nada sabemos de uma imagem, simplesmente inventamos, criamos narrativas, personagens, enredo. $\mathrm{O}$ fato é que, independente de lidar com a verdade ou com a fantasia, o objeto fotográfico é mesmo um pouco invisível. O que vemos, ou melhor, o que acreditamos nele ver, é o real congelado. Ainda acreditamos na imagem fotográfica.

Benjamin utiliza duas palavras para falar a respeito da aura: distância e inacessibilidade $^{16}$. Ele pretende confirmar que a aura não faz parte da imagem fotográfica, já que distância e inacessibilidade dizem respeito à imagem do culto. Mas poderíamos usar essas duas mesmas palavras para confirmar a aura da fotografia - da informação que ela guarda, e não a do objeto. A imagem fotográfica é uma imagem de distância e sem acesso possível, é imagem de mistério, de alguma verdade que não sabemos qual é $^{17}$. A fotografia acaba por se revelar mais como um meio de passagem entre o real congelado e os nossos olhos de agora do que como uma imagem reproduzida. Repetindo Barthes: uma foto é sempre invisível, só vemos o que ela guarda, e não a ela mesma. Numa pintura, ao contrário, podemos ver, antes mesmo do tema tratado, as pinceladas do artista, a fama e técnica do mesmo, o valor histórico e econômico. Uma fotografia fala sempre de outra coisa, o pedaço de papel acaba por ser um ausente diante da imagem, da mesma forma que a imagem é a presença de algo que não está mais. Talvez seja a fotografia esse grande jogo de ausências.

Benjamin também fala do "aqui e agora da obra de arte" perdido numa reprodução, a mais perfeita que seja. Esta "existência única" da obra de arte, Benjamin vê perdida na

Cadernos Benjaminianos, n. 3, Belo Horizonte, jan.-jun. 2011, p.43-54 
imagem técnica. Sim, algo disso tudo está realmente perdido. Mas talvez pudéssemos contestá-lo e dizer que na fotografia havia o negativo e que este era o original. Sendo original, os valores de autenticidade e unicidade estariam intactos. Pra ir um pouco mais longe, quando as primeiras imagens fotográficas foram fixadas em placas sensibilizadas, elas eram imagens únicas, não reproduzíveis. Por irônico que seja, a fotografia nasceu como objeto único. Mas, voltando a Benjamin, existe um "aqui e agora” perdido no objeto fotográfico, já que ele pode ser repetido incontáveis vezes. Por outro lado, existe um "aqui e agora" irrepetível, único, definitivo: a imagem impressa pela luz, ou, novamente com Flusser, a informação. A fotografia é a única imagem que fala de um "aqui e agora" no sentido mais literal do termo. Quando olhamos uma imagem fotográfica, este "aqui e agora" existe e está perdido. Sempre estará perdido o instante que se torna imagem. Está neste ponto, ao meu ver, um grande candidato a detentor da aura fotográfica. Uma mesma imagem pode ser reproduzida mil vezes, um milhão de vezes, mas ela sempre vai falar de um único instante, irrepetível, irreproduzível. O "aqui e agora" deslocou-se do objeto para a informação que ele carrega. É Barthes quem afirma: "O que a Fotografia reproduz ao infinito só ocorreu uma vez: ela repete mecanicamente o que nunca mais poderá repetir-se existencialmente." ${ }^{\text {18 }}$ Isso traça um dos mistérios fotográficos, um dos artifícios mais cativantes e assustadores da imagem técnica.

Mas é interessante observar uma possível contradição do próprio Benjamin quando, em seu texto anterior "Pequena história da fotografia", ele fala de um "aqui e agora" da própria fotografia:

(...) a técnica mais exata pode dar às suas criações um valor mágico que um quadro nunca mais terá para nós. Apesar de toda a perícia do fotógrafo e de tudo o que existe de planejado em seu comportamento, o observador sente a necessidade irresistível de procurar nessa imagem a pequena centelha do acaso, do aqui e agora, com a qual a realidade chamuscou a imagem, de procurar o lugar imperceptível em que o futuro se aninha ainda hoje em minutos únicos, há muitos extintos, e com tanta eloquência que podemos descobri-lo, olhando pra trás. ${ }^{19}$

"A pequena centelha do acaso, do aqui e agora". Parece existir para Benjamin, neste texto, o instante mágico da fotografia que, por mais reproduzido que seja o objeto, cria uma espécie de aura. O "aqui e agora" pertence à outra instância na imagem, mas definitivamente não se perdeu por completo.

Outro ponto que me chama a atenção no trecho de Benjamin é quando ele diz que "a técnica mais exata pode dar às suas criações um valor mágico que um quadro nunca mais terá para nós”. Dessa forma, o autor supõe que a própria pintura não tem mais uma magia (aura?) que a fotografia passa a ter, o que contradiz o que ele vai escrever depois no outro ensaio sobre a imagem técnica. Se existe um "aqui e agora" do objeto da pintura, há um outro "aqui e agora" que pertence à fotografia que parece, neste momento para Benjamin, ter maior valor. É interessante também quando ele fala do fotógrafo e do observador, porque as duas instâncias são colocadas, ambas, de forma ativa na produção da imagem. O fotógrafo a realiza tecnicamente (não somente, mas Benjamin tendia a acreditar nisso), mas o olhar do observador também cria o que vê. Isso é algo mais que clichê hoje em dia, mas naquela época talvez não fosse tão comum este pensamento sobre a recepção da

Cadernos Benjaminianos, n. 3, Belo Horizonte, jan.-jun. 2011, p.43-54 
imagem. Quanto ao gesto do fotógrafo que, lendo Benjamin, percebemos haver uma ideia de mecanicidade, pura técnica, no sentido de que qualquer um poderia fazer a mesma imagem, sabemos que isso não procede. Pelo fato da fotografia ser produzida por um aparelho, julgou-se que qualquer um poderia manipulá-lo e produzir a mesma imagem. Benjamin exaltou a nova técnica que liberava o uso das mãos, no sentido artesanal, e a imagem então era produzida por um mero aparato técnico: "Pela primeira vez no processo de reprodução da imagem, a mão foi liberada das responsabilidades artísticas mais importantes, que agora cabiam unicamente ao olho". ${ }^{20}$ Já sabendo que isso não faz sentido hoje em dia, é interessante observar uma afirmação de Barthes em $A$ câmara clara: "Para mim, o órgão do Fotógrafo não é o olho (ele me terrifica), é o dedo: o que está ligado ao disparador da objetiva, ao deslizar metálico das placas" ${ }^{\text {21 }}$. Barthes faz o caminho inverso à teoria de Benjamin: as mãos voltam para a imagem fotográfica, porque são elas que dizem respeito ao instante exato da imagem, e a fotografia guarda, na sua essência, uma forte ideia de tempo, de temporalidade.

Seria interessante também pensar a fotografia como fragmento do mundo - já muitos teóricos pensaram-na dessa forma. Barthes disse que todas as fotografias do mundo formavam um labirinto (há um eco borgiano nisso, e tento imaginar o pensamento do argentino sobre a fotografia e seus tortuosos caminhos). Na modernidade, a ideia de fragmento tornou-se forte, em especial com o Romantismo Alemão. No fragmento há sempre algo da totalidade, é como se cada ínfimo pedaço apontasse para um todo invisível. A fotografia é um pedaço do mundo, do mundo das imagens, do mundo dos acontecimentos passados e da memória. Talvez a sua aura esteja, também, nesse lugar de recorte do real, talvez a aura exista não na imagem fotográfica, mas no próprio real que ela não mostra. A fotografia é a presença de uma ausência, a ausência do próprio mundo em sua totalidade. E, sendo fragmento, ela é livre, ela pode significar-se e resignificar-se infinitamente, criando e recriando quantas ideias de mundo ela desejar.

Como cada foto é apenas um fragmento, seu peso moral e emocional depende do lugar em que se insere. Uma foto muda de acordo com o contexto em que é vista: assim, as fotos de Minamata tiradas por Smith parecerão diferentes numa cópia de contato, numa galeria, numa manifestação política, num arquivo policial, numa revista de fotos, numa revista de notícias comuns, num livro, na parede de uma sala de estar. Cada uma dessas situações sugere um uso diferente para as fotos mas nenhuma delas pode assegurar seu significado. A exemplo do que Wittgenstein afirmou sobre as palavras, ou seja, que o significado é o uso - o mesmo vale para cada foto. E é dessa maneira que a presença e a proliferação de todas as fotos contribuem para a erosão da própria noção de significado, para esse loteamento da verdade em verdades relativas, que é tido como algo fora de dúvida pela moderna consciência liberal. ${ }^{22}$

Outro dos tantos mistérios da fotografia: o que ela significa? O que uma imagem num pedaço de papel significa? O que reencontramos do real ali? Na realidade, vivemos numa ilusão de encontrar o passado nas imagens. Talvez encontremos um resquício dele. Há um trecho do livro do Vilém Flusser que me intriga:

A mania fotográfica resulta em torrente de fotografias. Uma torrente-memória que a fixa. Eterniza a automaticidade inconsciente de quem fotografa. Quem 
contemplar álbum de fotógrafo amador, estará vendo a memória de um aparelho, não a de um homem. Uma viagem para a Itália, documentada fotograficamente, não registra as vivências, os conhecimentos, os valores do viajante. Registra os lugares onde o aparelho o seduziu para apertar o gatilho. Álbuns são memórias "privadas" apenas no sentido de serem memórias de aparelho. $^{23}$

Talvez tenhamos mesmo a doce ilusão de ter o passado registrado num álbum - a ilusão de conservar a memória. Lembro de Sontag dizendo que a fotografia é uma proteção contra a ansiedade. Ansiedade esta que vem exatamente do tempo e da sua passagem. A ideia de progresso acelerou o tempo vertiginosamente. E, não por acaso, foi o progresso quem criou a câmera fotográfica, o veneno e o antítodo são criados simultaneamente. Então, voltando à pergunta: o que uma imagem num pedaço de papel significa? O que posso eu encontrar de mim mesma aos 5 anos de idade abraçada ao meu pai que agora já está morto? Encontro fantasmas, meu pai e eu. Mas um dia, em algum lugar perdido do tempo, houve um abraço e houve uma luz refletida desse abraço em direção a uma película sensível. É tudo o que podemos saber de uma fotografia.

Chegamos, neste ponto, a um bonito trecho do ensaio de Benjamin, quando ele fala sobre a aura que resta nos retratos, nas fotografias de rostos humanos:

Mas o valor de culto não se entrega sem oferecer resistência. Sua última trincheira é o rosto humano. Não é por acaso que o retrato era o principal tema das primeiras fotografias. O refúgio derradeiro do valor de culto foi o culto da saudade, consagrada aos amores ausentes ou defuntos. A aura acena pela última vez na expressão fugaz de um rosto, nas antigas fotos. É o que lhes dá sua beleza melancólica e incomparável. ${ }^{24}$

Se a aura ainda acena nessas imagens, isso diz respeito, sim, ao valor afetivo, ao valor de saudade. Mas também diz respeito ao valor de real, do "ter acontecido", o que Barthes chamou de o " isso foi" da fotografia ${ }^{25}$. Quando olhamos nossos antigos álbuns, as antigas fotos familiares em que geralmente há menos vivos do que mortos, mais do que pessoas, nós vemos o tempo passado, e sabemos que, um dia, aquilo aconteceu. O olhar que lançamos, hoje, para aquele tempo congelado, reaviva algo do mundo dos mortos: "é a imagem viva de uma coisa morta" ${ }^{26}$. Talvez a aura esteja em torno desse lugar impossível, de tornar carne e osso o que não existe mais.

Falando do olhar, a fotografia também inaugura um jogo de olhares através da imagem. Um dia, um fotógrafo nos mira com o aparelho e nós miramos a câmera. Outro dia, outros olhos miram a imagem captada naquele instante. Nenhum olhar se cruza: nem os do fotografado com os do fotógrafo e nem os do futuro observador da imagem pronta com os olhos impressos na imagem. Ninguém nunca se olhou diretamente, mas todos podem se ver. No ensaio "Sobre alguns temas em Baudelaire", Benjamin comenta algo sobre isso:

O que devia ser sentido como elemento inumano, mesmo mortal, por assim dizer, na daguerreotipia, era o olhar para dentro do aparelho (prolongadamente, aliás), já que o aparelho realmente registra a imagem do homem sem lhe devolver o olhar. É, contudo, inerente ao olhar essa expectativa de ser 
correspondido por quem o recebe. Onde essa expectativa é correspondida (...), aí cabe ao olhar a experiência da aura, em toda a sua plenitude. ${ }^{27}$

É interessante pensar que o olhar é, sim, devolvido, mas em outro tempo. Na fotografia, nada se olha diretamente, e quando a imagem está pronta, tudo já é tarde demais. A fotografia sempre fala de algo perdido, dos olhares ao tempo. Para Susan Sontag, "Todas as fotos são memento mori" - lembra-te de que vais morrer. Talvez os olhares que não se cruzam sejam uma lembrança, também, disso: há algo perdido. É Barthes quem vê o terror da fotografia no que ele chama de "o retorno do morto" 28 . E Sontag continua: "Tirar uma foto é participar da mortalidade, da vulnerabilidade e da mutabilidade de outra pessoa (ou coisa). Justamente por cortar uma fatia desse momento e congelá-la, toda foto testemunha a dissolução implacável do tempo."29 Olhar uma fotografia é como olhar os olhos mortos de um cadáver: algo existiu ali, mas nada mais nos é dado. A devolução do olhar acontece de alguma outra forma que nos é misteriosa. Todas as fotografias talvez formem um labirinto - um labirinto de vivos e mortos, onde o que está vivo se parece com um morto e vice-versa. Na imagem fotográfica, vivos e mortos são iguais. Por isso o terror, quando prestamos um pouco mais de atenção nas imagens. Lidamos com fotografias tão cotidianamente que mal as percebemos. Mas elas guardam, repito, algo de tão misterioso que creio jamais ter havido, na história das sociedades, algo tão pleno de aura.

\section{A ainda (e sempre) inevitável aura das coisas}

A aura sempre estará em algum lugar, porque ela é algo que está antes nos nossos próprios olhos do que nas coisas que olhamos. Se algo muda da nossa percepção, ou do mundo, diversos reajustes são feitos entre as coisas e os nossos olhos, até que, por fim, volta tudo para um mesmo lugar, lugar de distância e de unicidade. A verdade é que a aura nunca está nas coisas, mas em como olhamos as coisas. Sabemos que é diferente o olhar que lançávamos à pintura em relação ao olhar que lançamos à fotografia. Mas essa diferença em nada faz perder a magia que os nossos olhos sentem ao mirar uma imagem de qualquer espécie. A fotografia faz-nos aproximar de uma ideia de real completamente questionável, mas ainda assim fazemos da realidade a grande matéria fotográfica. Em termos práticos, uma foto pode ser somente a prova de existência, prova de um instante de existência, nada sabendo-se do real que ela propõe. E a beleza ronda este lugar, lugar sempre de mistério, um lugar de vivos e mortos, de possíveis e jamais acontecidos. Talvez por aí esteja a aura da fotografia, no desconhecido que ela propõe e revela. Baudelaire se enganou quando viu o "verdadeiro" na fotografia e opôs isso à beleza. A beleza existe na imagem fotográfica justo porque dela nada sabemos. Talvez a aura tenha a ver com essa instância do desconhecido - da distância, mais uma vez citando Benjamin. A luz irradiada pelas coisas imprime o papel, há sempre um resto, um resquício, algo do original que está na fotografia. Mas a fotografia é a imagem da perda. E o que perdemos torna-se, geralmente, o que guardamos com maior afeição.

Para terminar, uma lembrança. No filme "Les parapluies de Cherbourg", de Jacques Demy (1964), a jovem mocinha, interpretada por Catherine Deneuve, sofre porque o namorado está longe, lutando na guerra. Dia e noite ela despedaça-se de saudade diante de uma fotografia que tem dele guardada. Um dia, ela resolve parar de olhar a fotografia,

Cadernos Benjaminianos, n. 3, Belo Horizonte, jan.-jun. 2011, p.43-54 
porque sente que está se esquecendo do rosto dele. Ao pensar no homem que está longe, ela só consegue se lembrar da sua imagem congelada em sais de prata.

\begin{abstract}
This paper aims at studying Benjamin's theory of the destruction of the aura and its possible reinvention in photoghraphic image through the characteristic shift of modern man's perception. Photography broke as an emblematic technical image with the standard paradigms of authenticity and unicity of image which prevailed up to the 19th century, and brought into light new revealing aspects of the aura, as well as new values of authenticity and unicity focusing less on objects than on the information they carry.
\end{abstract}

Keywords: Walter Benjamin. Aura. Photography.

\title{
Referências Bibliográficas
}

BARTHES, Roland. A câmara clara. Nota sobre a fotografia. Rio de Janeiro: Nova Fronteira, 1984. 188 p.

BAUDELAIRE, Charles. O público moderno e a fotografia. Disponível em http://www.entler.com.br/textos/baudelaire2.html

BENJAMIN, Walter. Magia e Técnica, Arte e Política: ensaios sobre literatura e história da cultura. 7. ed. São Paulo: Brasiliense, 1994. 256 p. $1989.272 \frac{\mathrm{p} .}{}$

Charles Baudelaire um lírico no auge do capitalismo. São Paulo: Brasiliense,

FLUSSER, Vilém. Filosofia da caixa preta: Ensaios para uma futura filosofia da fotografia. Rio de Janeiro: Relume Dumará, 2002. 84 p.

SONTAG, Susan. Sobre fotografia. São Paulo: Companhia das Letras, 2004. 224 p.

\section{Notas}

${ }^{1}$ Fotografia de Nicéphore Niepce. Considerada a primeira fotografia bem-sucedida, ou seja, fixada e permanente. França, 1826.

${ }^{2}$ Hércules Florence (1804-1879), inventor, desenhista.

${ }^{3}$ SONTAG, Sobre Fotografia, p. 26.

${ }^{4}$ BAUDELAIRE, O público moderno e a fotografia, 1859.

${ }^{5}$ Publicado em 1936. Benjamin já havia escrito sobre fotografia no seu outro ensaio “ Pequena história da fotografia”, de 1931. Neste já aparece o conceito de aura.

${ }^{6}$ BENJAMIN, Magia e Técnica, Arte e Política , p. 170.

${ }^{7}$ IBIDEM, p. 169. 
${ }^{8}$ BARTHES, A câmara clara, p. 25.

${ }^{9}$ BARTHES, A câmara clara, p. 27.

${ }^{10}$ BENJAMIN, Magia e Técnica, Arte e Política, p. 104.

${ }^{11}$ SONTAG, Sobre Fotografia, p. 28

${ }^{12}$ Ver: OTTE, Georg. A reprodutibilidade técnica da obra cinematográficaRepresentação ou clonagem? Uma análise crítica de um conceito básico de Walter Benjamin.

${ }^{13}$ FLUSSER, Filosofia da caixa preta, p. 47.

${ }^{14}$ BARTHES, A câmara clara, p. 16.

${ }^{15}$ SONTAG, Sobre Fotografia, p. 33.

${ }^{16}$ BENJAMIN, Charles Baudelaire um lírico no auge do capitalismo, p. 140.

17 "Estritamente falando, nunca se compreende nada a partir de uma foto. (...) a representação da realidade pela câmera deve sempre ocultar mais do que revela". SONTAG, Sobre fotografia, p. 33-34.

${ }^{18}$ BARTHES, A câmara clara, p.13.

${ }^{19}$ BENJAMIN, Magia e Técnica, Arte e Política, p. 94.

${ }^{20}$ IBIDEM, p. 167.

${ }^{21}$ BARTHES, A câmara clara, p. 30.

${ }^{22}$ SONTAG, Sobre Fotografia, p. 122.

${ }^{23}$ FLUSSER, Filosofia da caixa preta, p. 54.

${ }^{24}$ BENJAMIN, Magia e Técnica, Arte e Política, p. 174.

${ }^{25}$ BARTHES, A câmara clara, p. 115.

${ }^{26}$ IBIDEM, p. 118.

${ }^{27}$ BENJAMIN, Charles Baudelaire um lírico no auge do capitalismo, p. 139.

${ }^{28}$ BARTHES, A câmara clara, p. 20.

${ }^{29}$ SONTAG, Sobre Fotografia, p. 26. 